\title{
Bonding Condition Evaluation using a Melting-Point-Change Type Conductive Paste
}

\author{
Kaoru SUGIMOTO****, Tomohisa YAGI**, \\ Hideo HONMA ${ }^{* * *}$ and Mitsuhiro WATANABE***
}

(Received July 5, 2018)

\begin{abstract}
Nowadays advanced board structures are made of two different circuit boards interconnected to each other. As these circuit boards are made of different materials and have to go through different manufacturing processes, the use of a specific conductive paste is needed for a reliable interconnection. To realize this complex structure, we worked on the development of an innovative conductive paste overcoming the weaknesses of the conventional one. It is a melting-point-change type conductive paste in which a large spherical copper $(\mathrm{Cu})$ powder is used as a conductive filler and an alloy of tin $(\mathrm{Sn})$ and bismuth (Bi) is coated on its surface. The conductive paste is expected to stabilize the bonding by tolerating the scatter of the thickness, it also has to maintain a long-term electrical reliability. In this paper, we determined the fundamental composition of the paste to answer these needs. To evaluate the performance of the bonding we studied the influence of the electrical reliability of the paste at its optimum bonding condition, the aggregability of the resin and the bonding strength. Finally, we created a complex structure with the paste to analyze the tolerance of the bonding height and its electrical resistance through a thermal cycle (TC) test.
\end{abstract}

Key Words: Circuit Boards, Conductive Paste, Melting-point-change, Interconnection Structure

\section{Introduction}

The High-end field of circuit boards is developing a new product segment where circuit boards are connected to each other. These circuit boards are made of different materials and are going through different manufacturing processes. The conductive paste technology is expected to substitute the mechanical compound method. It is broadly used as a via connection technology in the circuit boards. ${ }^{1)-11)}$ In fact until now, to create a reliable circuit board interconnection, the paste was required to overcome its weakness. With the complexification of circuit board structures the conductive paste as a via connection technology in the circuit board cannot ensure a reliable interconnection. This is why there is a big demand for a new paste meeting the new higher requirements for a reliable interconnection. However, evolving from a simple circuit board interconnection to a complex one makes the paste re-melting and the connection reliability management rather difficult.

Fig. 1 shows an example of two high-density circuit boards connected to one another. A previous study reported the laminating conditions for high multilayer and high performance circuit boards structures using a compression type conductive paste. ${ }^{12)}$ This study showed that the laminating condition of the high multilayer circuit board had an influence on the paste compression ratio at the vias forming. In the report, although the optimum compression range for the paste setting was found, securing each high-multilayer board electrical reliability remains difficult.

Considering these issues, we worked on the development of a conductive paste matching the requirements for a reliable composite structure interconnection. This conductive paste is a melting-point-change type paste in which a large spherical $\mathrm{Cu}$ powder (particle diameter $25 \mu \mathrm{m}$ to $50 \mu \mathrm{m}$ ) is used as a conductive filler and an alloy of $\mathrm{Sn}$ and $\mathrm{Bi}$ is coated on its surface. The $\mathrm{Cu}$ filler particularity is that it would not re-melt after the

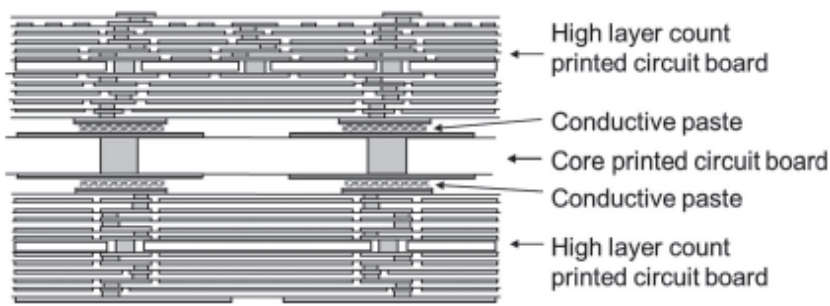

Fig. 1 An example of high multilayer circuit boards interconnection structure.

*富士通インターコネクトテクノロジーズ株式会社 ビジネス開発統括部（７ 211-8588 神奈川県川崎市中原区上小田中 4-1-1 (本 -1014) )

Fujitsu Interconnect Technologies Limited, Business Development Division

(1-1, Kamikodanaka 4-chome, Nakahara-ku, Kawasaki 211-8588, Japan (Company Mail No./Hon-1014))

**富士通クオリティ・ラボ株式会社（７ 674-8555 兵庫県明石市大久保町西脇 64 番地 富士通明石工場内）

Fujitsu Quality Laboratory Limited (64-Nishiwaki,Okubo-cho, Akashi-shi, Hyogo 674-8555, Japan (Fujitsu LTD, Akashi Office))

$* * *$ 関東学院大学 大学院工学研究科 ( T 250-0042 神奈川県小田原市荻窪 1162-2)

Graduate School of Engineering, Kanto Gakuin University (1162-2, Ogikubo, Odawara-shi, Kanagawa 250-0042, Japan) 
first heating and curing.

In this paper, we established the particle size of the $\mathrm{Cu}$ filler, the compound ratio of the resin composition and the bonding process condition (temperature, pressure, time). The electrical resistance stability was measured by a TC test after the bonding. Furthermore, the height and diameter of the paste indispensable for the stability of the bonding were observed. In the circuit connection demonstration experiment, by using the TEG (test element group) board with a daisy chain circuit pattern, the electrical resistance value after the joining was observed, the height tolerance clarified and the resistivity change calculated with a TC test.

\section{Experimental procedure}

2.1 Evaluation of the bonding condition impact of the electrical resistance

Optimum circuit board bonding conditions must be determined by the process of heating while pressurizing. Experimental conditions were set as follow: two filler particle diameters $(32.5 / 50$ ( $\mu \mathrm{m}), 2 \mu \mathrm{m}$ Sn-Bi coating), three different contents (89/90/91 (wt\%)), three bonding temperatures $\left(150 / 175 / 200\left({ }^{\circ} \mathrm{C}\right)\right)$, and three bonding pressures $(0.49 / 1.47 / 2.45(\mathrm{MPa}))$ based on the design of experiments (DOE). The electrical resistance variation was found by applying repeated TC stress on these eighteen combination. The criteria have determined that the change rate of the electrical resistance had to be within a $10 \%$ small range when applying a $-40{ }^{\circ} \mathrm{C}$ to $+150{ }^{\circ} \mathrm{C}$ TC stress for 500 times or more.

As regard measuring equipment, I-V characteristics ware acquired with a DC stabilized power supply (Kikusui Electronics PWR 400L) and a strain measuring unit for voltage monitoring (Keyence NR-ST 04) was used in the design of optimum conditions. A temperature cycle chamber (Kusumoto Chemical WINTECH NT1010) was used for the long-term reliability.

\subsection{Evaluation of paste bonding strength}

It is necessary to ensure the stability of the bonding strength even with a variation in the bonding conditions and the particle size of the spherical $\mathrm{Cu}$ powder. Therefore, experiments were conducted to increase the strength of the joint by improving the adhesive component essential for the paste material. This paste material is made of $20 \mu \mathrm{m}$ to $38 \mu \mathrm{m} \mathrm{Cu}$ particle $(2 \mu \mathrm{m} \mathrm{Sn-Bi}$ coating) as conductive filler (content $89 \mathrm{wt} \%$ ), an epoxy resin (bisphenol $\mathrm{F}$ type + naphthalene type) as additive, and a curing agent (MTHPA : Methyl-tetra-hydro-phthalic Anhydride Acid) as reference. In the experiment, the adhesion strength was changed by adding a thixotropic agent and by changing the curing agent: acid anhydride ${ }^{13)}$. Table 1 shows the paste sample conditions. A paste was applied to a $110 \mathrm{~mm}^{2}$ bonding surface of the $\mathrm{Cu}$ test piece, for $90 \mathrm{~min}$ under $2.45 \mathrm{MPa}$ and $150^{\circ} \mathrm{C}$ and subjected it to a tensile test.
As regard bonding strength measurements, a tensile tester (Instron INSTRON 5581) was used and the cross section observation was made by using a metallurgical microscope (Nikon OPTIPHOTO200).

\subsection{Evaluation of the paste compression amount}

This experiment was conducted to clarify the relationship between the bonding pressure and the compression amount of the paste in order to obtain an ideal condition to realize a stable height after the paste bonding. The paste applied on the Si wafer $(20 \times$ $20 \mathrm{~mm}$ ) was sandwiched with another Si wafer $(20 \times 20 \mathrm{~mm})$, and pressed from 0.02 to $2.89 \mathrm{MPa}$, while being heated continuously until the curing temperature exceeded $180^{\circ} \mathrm{C}$. The change in height and in the applied diameter was measured though the variation of the load, and the pressure conditions to attain an ideal connection were confirmed.

As regard measurement equipment, a LSI replacer (Shibuya Kogyo DB200) for pressurized heating machine, a metallurgical microscope (Nikon OPTIPHOTO200) and X-ray line inspection apparatus (Shimadzu SMX-160V) were used.

2.4 Tolerance evaluation of the bonding height

A TEG board was used for the actual construction of the composite structure. Fig. 2 shows a schematic view of the TEG board where (a) is the image view after connection and (b) is the schematic view of the bonding pad layout. By connecting

Table 1 Paste conditions for bonding strength examination.

\begin{tabular}{|c|c|c|c|c|c|}
\hline \multirow{2}{*}{$\begin{array}{c}\text { Paste } \\
\text { type }\end{array}$} & \multirow{2}{*}{$\begin{array}{l}\text { Filler diameter }(\mu \mathrm{m}) \\
\text { (Si-Bi coating } 2 \mu \mathrm{m})\end{array}$} & \multirow{2}{*}{$\begin{array}{r}\text { Content } \\
(\mathrm{wt} \%)\end{array}$} & \multicolumn{3}{|c|}{ Resin conditions } \\
\hline & & & Epoxy resin & Curing agent & Additive \\
\hline 1 & $20-38$ & 89 & $\begin{array}{c}\text { bisphenol F type } \\
\text { + naphthalene }\end{array}$ & MTHPA * & - \\
\hline 2 & $20-38$ & 89 & $\begin{array}{l}\text { bisphenol } \mathrm{F} \text { type } \\
+ \text { naphthalene }\end{array}$ & MTHPA * & Thixotropic agent \\
\hline 3 & $20-38$ & 89 & $\begin{array}{l}\text { bisphenol F type } \\
+ \text { naphthalene }\end{array}$ & $\begin{array}{l}\text { Terpene-based } \\
\text { acid anhydride }\end{array}$ & - \\
\hline
\end{tabular}

(a)
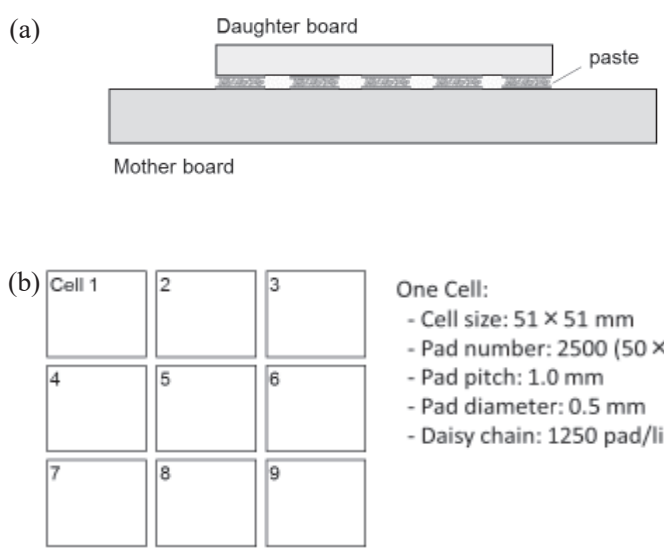

One Cell:

- Cell size: $51 \times 51 \mathrm{~mm}$

- Pad number: $2500(50 \times 50)$

- Pad pitch: $1.0 \mathrm{~mm}$

- Pad diameter: $0.5 \mathrm{~mm}$

- Daisy chain: $1250 \mathrm{pad} / \mathrm{line}$

Fig. 2 TEG board for interconnection structure.

(a) Interconnection structure image after bonding. (b) TEG patterns on board surface for measurement of bonding height and electric resistance. 
the daughter board (thickness: $4.2 \mathrm{~mm}$ ) to the mother board (thickness: $5.7 \mathrm{~mm}$ ), the electrical resistance of the connection part was measured to establish whether it was good or bad, and the tolerance of the optimum bonding height was determined by observing the cross section of the structure. The bonding process consisted in pre-curing the bonding sheet on the mother board and bonding the daughter board after the paste is filled. The pre-curing conditions were set to $27 \mathrm{sec}$ vacuum, $0.1 \mathrm{MPa}$ and $47^{\circ} \mathrm{C}$ for 10 sec. The condition for the board bonding were: $2.26 \mathrm{MPa}, 170^{\circ} \mathrm{C}$ for $90 \mathrm{~min}$. Regarding the verification of the long-term reliability, the change rate of the electrical resistance was observed through a TC test $\left(-65^{\circ} \mathrm{C}\right.$ to $+150^{\circ} \mathrm{C}, 500$ cycles $)$.

As regard measurement equipment, a metallurgical microscope (Nikon OPTIPHOTO200), a resistance tester (Yokogawa Electric Digital Multimeter 7561/7562) and a TC cycle chamber (Kusumoto Chemical WINTECH NT1010) were used.

\section{Results and discussion}

\subsection{Electrical resistance change by the bonding condition}

In order to set optimum conductive paste bonding conditions the distribution of whole composition was studied. Fig. 3 shows the L18 orthogonal table in DOE, and the plot results of the average changing rate of the electrical resistance. This change rate reveals the difference between the electrical resistance value obtained from eighteen different combinations before and after the thermal cycle experiment. By comparing the two diameters, we can observe a lower change rate for the $32.5 \mu \mathrm{m}$ diameter group combination. In this results, the lowest change rate appeared at the $\mathrm{Cu}$ diameter $32.5 \mu \mathrm{m}$ and curing temperature $150{ }^{\circ} \mathrm{C}$ combination group. The change rate for this combination was near $0 \%$. From this result, each $\mathrm{S} / \mathrm{N}$ ratio of control factors were clear and the optimum condition presumed. A series of conditions estimated to be optimal for the bonding process and another one for the comparison are shown in Table 2.

Fig. 4 shows the result of the TC re-test was carried out under these conditions. Fig. 4(a) shows the results of I-V characteristics obtained by studying the relation between the applied current (I) and the voltage (V) changing according to the current (I). In the parameter condition for comparison, after the TC test, the voltage (V) difference is $-11.6 \%$ at $2 \mathrm{~A}$. However, when setting the optimum condition parameter, there was no change in the $\mathrm{I}-\mathrm{V}$ characteristics after the TC test, and a $0.4 \%$ ideal rate change was confirmed. Fig. 4(b) shows a bonding cross sectioning of the I-V characteristics stable state, a strong bonding state it can be observed on each $\mathrm{Cu}$ particles. The I-V characteristics stability is shown by the combination of small particles and $150^{\circ} \mathrm{C}$ curing temperature. This shows that because the contact area and density is increased with the reduction of the particles diameter, an effective intermetallic compound (IMC) is formed

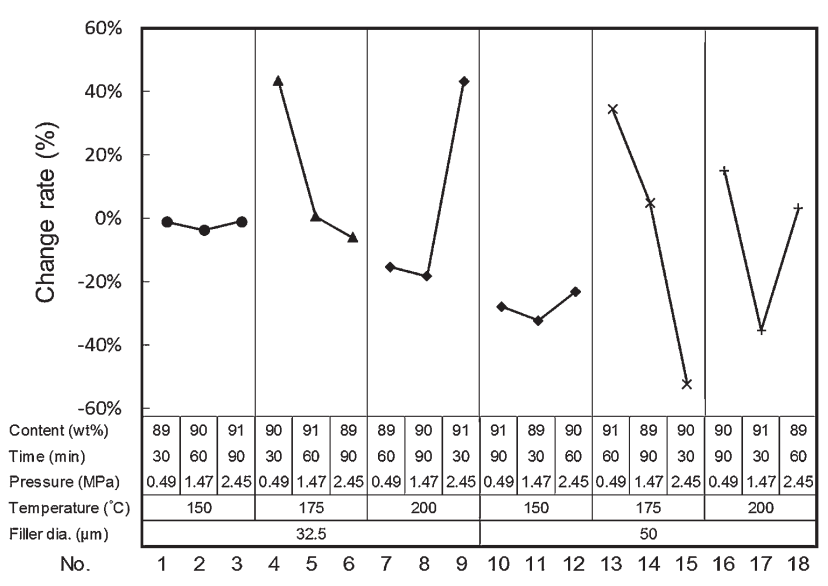

Fig. 3 Rate of change results of electrical resistance, and experimental factors based on the L18 orthogonal table in the design of experiments (DOE)

Table 2 Estimated optimum bonding condition by a $\mathrm{S} / \mathrm{N}$ ratio.

\begin{tabular}{cccc}
\hline & & Optimum condition & Comparison condition \\
\hline Conductive filler diameter & {$[\mu \mathrm{m}]$} & 32.5 & 50 \\
Connection Temperature & {$\left[{ }^{\circ} \mathrm{C}\right]$} & 150 & 175 \\
Connection pressure & {$[\mathrm{MPa}]$} & 2.45 & 0.49 \\
Connection time & {$[\mathrm{min}]$} & 90 & 60 \\
Conductive filler content & {$[\mathrm{wt} \%]$} & 89 & 91 \\
\hline
\end{tabular}

(a)

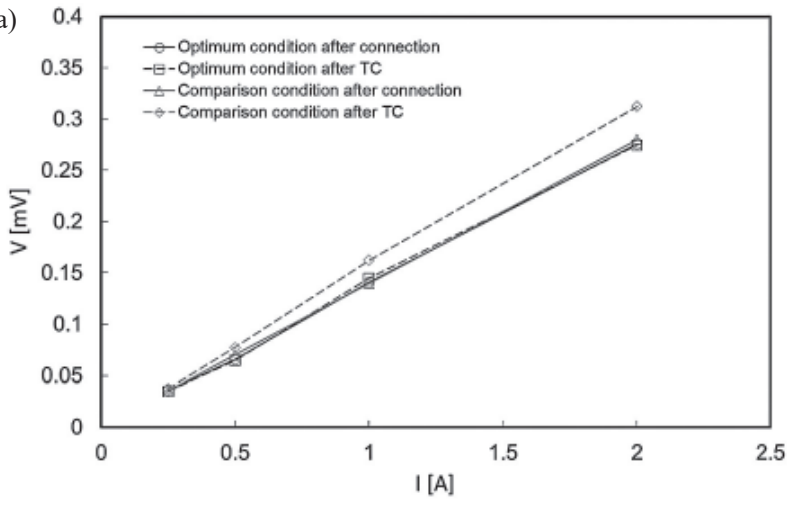

(b)

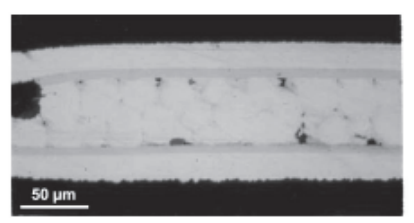

Fig. 4 Results of TC re-test under the optimum condition. (a) Results of the I-V properties showing the optimum reproducibility of the experimental conditions. (b) Bonding cross sectioning of the stable I-V characteristics.

between the $\mathrm{Cu}$ core and $\mathrm{Sn}-\mathrm{Bi}$ alloying coating. We can observe this on Fig. 4(b). The Sn-Bi eutectic temperature $\left(137^{\circ} \mathrm{C}\right)$, the curing peak temperature $\left(142^{\circ} \mathrm{C}\right)$ and the curing reaction of the bonding sheet (from $130^{\circ} \mathrm{C}$ ) and their timing are set according to 
the curing temperature $\left(150^{\circ} \mathrm{C}\right)$. Thus, this timing is interpreted to be in balance. Thus, the electrical reliability of the paste can be obtained by maximizing the contact area between the $\mathrm{Cu}$ particles. By appropriately selecting the pressure of the bonding, the curing temperature and the time, it is possible to obtain a bonded state that balances appropriately the compounding ratio of the $\mathrm{Cu}$ particles and ensures the electric reliability even after the thermal cycle.

\subsection{Aggregation state and bonding strength of paste}

In order to set the optimum process conditions for the conductive paste, the distribution of the entire composition including the bonding material was examined. The bonding strength of the paste material in section 3.1 often varies depending on the conditions of heating and pressure at the time of bonding. Therefore, while taking into consideration the bonding stability of the paste during the heating process, we examined the improvement of the adhesive component for a steadier bonding strength. Fig. 5 shows a cross sectioning comparing the bonding state in which the difference in strength occurs at the bonding portion of the paste. Fig. 5(a) shows an example of how $\mathrm{Cu}$ particles are dispersed due to poor bonding conditions. The bonding sheet fluidity associated with the heating during the structure construction is most likely the reason for this filling state. Fig. 5(b) is an ideal form with a strong bonding strength. $\mathrm{Cu}$ particles collectively aggregate at the center, and the contact area to be alloyed is also large. It is necessary for the composition of the paste material that such agglomeration change stays small even after a change in the behavior of the bonding sheet at the time of pressurization and heating. The bonding strength and the aggregability after the curing was investigated in order to determine the resin composition to ensure an ideal density to maximize the bond of the $\mathrm{Cu}$ particle. Fig. 6 shows the state of the test piece after the bonding experiment. The bonding area is the overlapping inner side of each test pieces. Fig. 6(a) shows the interface of the paste type 1 with the basic composition as a reference. The central part of both test pieces is an aggregated part in which the $\mathrm{Cu}$ particles of the paste are cured. In contrast, Fig. $6($ b) is a paste type 2 to which a thixotropic agent is added. We observed that the aggregation state was clearly improved in comparison with the paste type 1. In addition, Fig. 6(c) is a paste type 3 with a different curing agent. Its aggregation state is clearly (a)

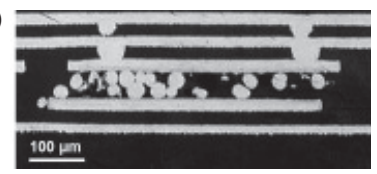

Fig. 5 Cross sectioning of bonding condition cured under 2.45 $\mathrm{MPa}, 150^{\circ} \mathrm{C}$ for $90 \mathrm{~min}$. (a) Condition of few filler. (b) Ideal connected condition. inferior to Fig. 6(b). However there is no big difference from the reference aggregation state of the paste type 1 .

Next, the results of the numerical comparison of the bonding strength are shown in Fig. 7. By visual observation, the state of aggregation appeared to be a slight different, whereas the strength difference appear larger. Compared to the reference paste with a basic composition, the type 2 added thixotropic agent shows a $42 \%$ improvement effect while the paste type 3 with the altered curing agent shows a $49 \%$ reduction. This is believed to be due to the addition of the thixotropic agent improving the printability when applying the paste, allowing the $\mathrm{Cu}$ particles to be easily bonded by maintaining a high viscosity even at the time of curing after the coating.

On the other hand, the strength remarkably decreased in the paste type 3 in which the curing agent was changed. In this case, the curing agent was also changed to a highly viscous one in order to suppress the outflow of $\mathrm{Cu}$ particles, but expected effects could not be obtained. This is believed to be due to the fact that the adhesion force of the resin itself contributes greatly to the bonding strength, and therefore modified curing agent was inferior in reactivity to the reference and the adhesive strength of the resin was also lowered. From this result, it can be interpreted that the method of increasing the viscosity with the curing

(a)
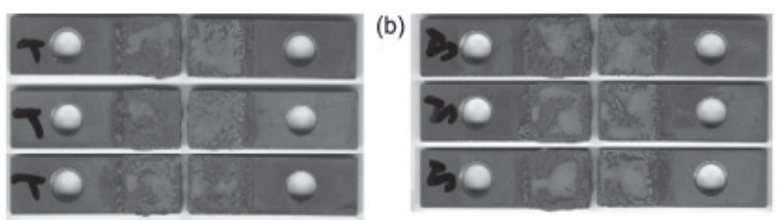

(c)

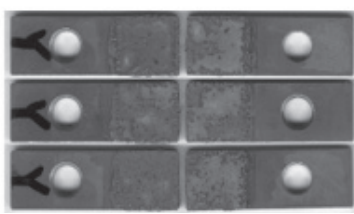

(d)

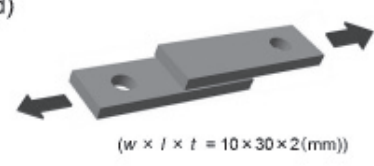

Fig. 6 Comparison of the aggregation state of paste after tensile test. (a), (b), (c) are paste type 1, 2, 3. (d) Test piece: connected area is $110 \mathrm{~mm}^{2}$.

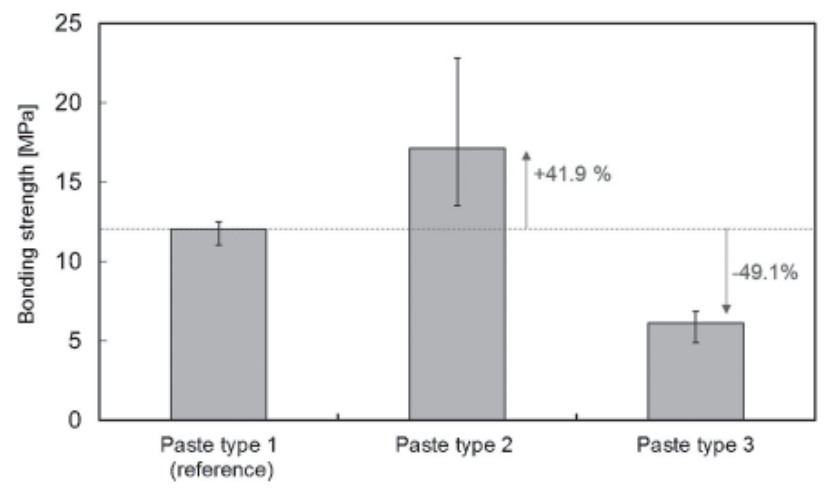

Fig. 7 Comparison of bonding strength of paste by tensile test. 
agent eventually hindered the agglomeration of the $\mathrm{Cu}$ particles and further decreased the adhesive strength of the resin itself. Therefore, it can be said that the increasing thixotropy is the most effective approach to increase cohesiveness.

\subsection{Paste compression amount}

By observing the change in height according to the pressure applied to the aggregated paste itself, the relationship between the pressure at which the bonding was stabilized and the crushed amount was confirmed. Fig. 8 shows a cross-sectional photograph (left side) of the crushed state of the paste for each load and an X-ray photograph (right side) showing a change in the coating diameter. The increase in paste diameter shows little change from $0.46 \mathrm{MPa}$ to $1.34 \mathrm{MPa}$, but from around $1.34 \mathrm{MPa}$ a sharp rise is observed, and the increase rate exceed $80 \%$ at $2.84 \mathrm{MPa}$. Then, at $2.86 \mathrm{MPa}$, which is the largest load, X-ray is observed on a photograph short circuit between adjacent pastes.

Fig. 9 is a graph showing the dimensional change in the thickness direction and in the spread ratio in the planar direction. The height of the paste sharply decrease to a load near 0.46 MPa. Thereafter a stable height with little change according to the

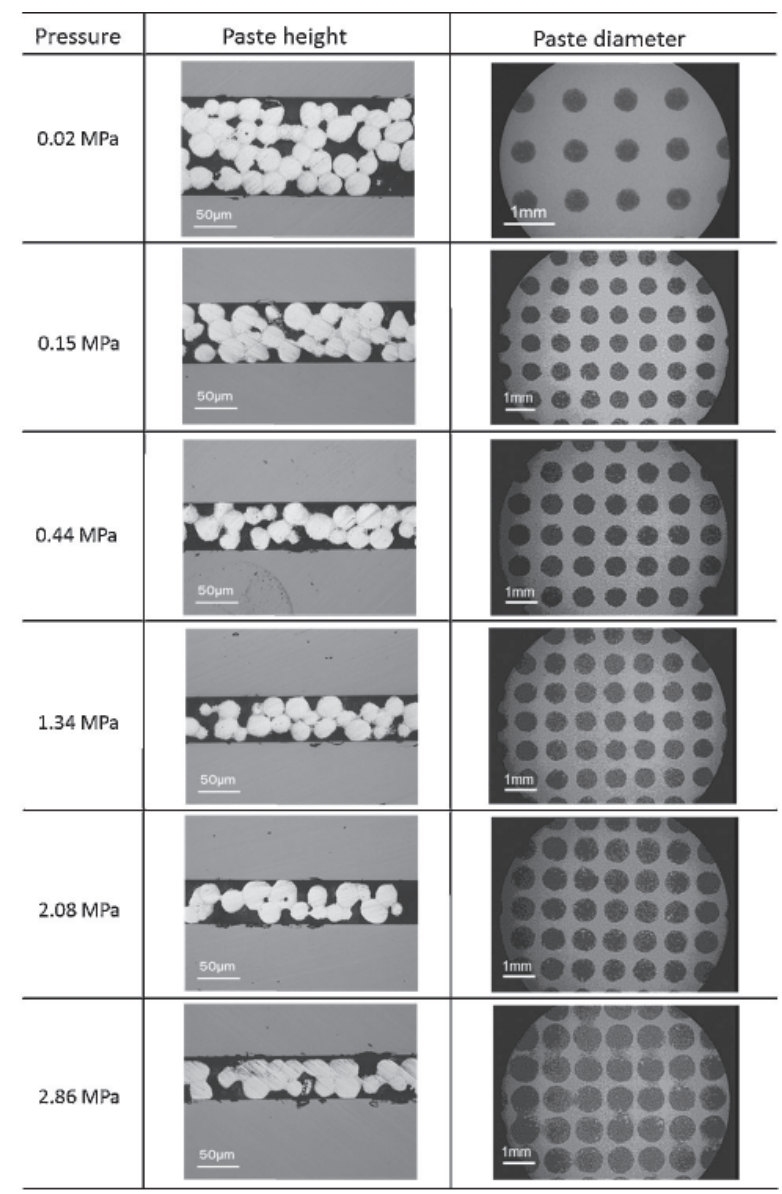

Fig. 8 Observation result of cross section of bonding height. Pressure was at 0.02 to $2.89 \mathrm{MPa}$, curing was heated continuously until $180^{\circ} \mathrm{C}$ is exceeded. increase of the load is kept. Furthermore, in the region above 2.08 $\mathrm{MPa}$, the height approaches the crush limit and its variation is extremely small. Therefore, when observing the entire load region we can see that, the crushed height variations from the vicinity of $0.46 \mathrm{MPa}$ are very small, the height of the bonding is almost determined, and the height is stable from 2.86 MPa.

From these results, it was found that keeping the load at about 1.5 MPa or less is the most suitable condition to keep a stable paste diameter. In particular, the rapid change in paste application diameter is believed to be due to the melt bonding of the coating metal between the $\mathrm{Cu}$ particles progressing as the $\mathrm{Cu}$ particles pressurization becomes larger than $1.34 \mathrm{MPa} . \mathrm{Cu}$ particles deformation is considered to be due to higher pressure and thereby its volume is extruded. ${ }^{14)}$ Since the periphery of each paste is in an open state and as the resin becomes highly liquid with the heating, the $\mathrm{Cu}$ particles may have been extruded with the synergy effect of the pressure.

The paste height behavior shows that the paste itself acts as a stopper, which means that the stable bonding height can be determined. This means that this conductive paste can be used in a relatively low load in the bonding process of the circuit board. At the same time, this leads to a reduction in the pressure applied to the bonding sheet, which makes the control of the pressurizing and the heating process easier. In this respect, the bonding sheet material can suppress the melting viscosity to a comparatively low level, and if the material having a small repulsive force against the bonding load can be adopted, excessive resin flow can be suppressed, the shape of the paste bond portion can be stabilized, and a highly reliable bonding can be obtained.

\subsection{Tolerance of bonding height}

Fig. 10 shows the cross section of the connecting part in the interconnection structure by TEG board. The bonding state of $\mathrm{Cu}$ fillers in the paste connecting the upper and lower pad is observed, both cross sections shows a good resistances state.

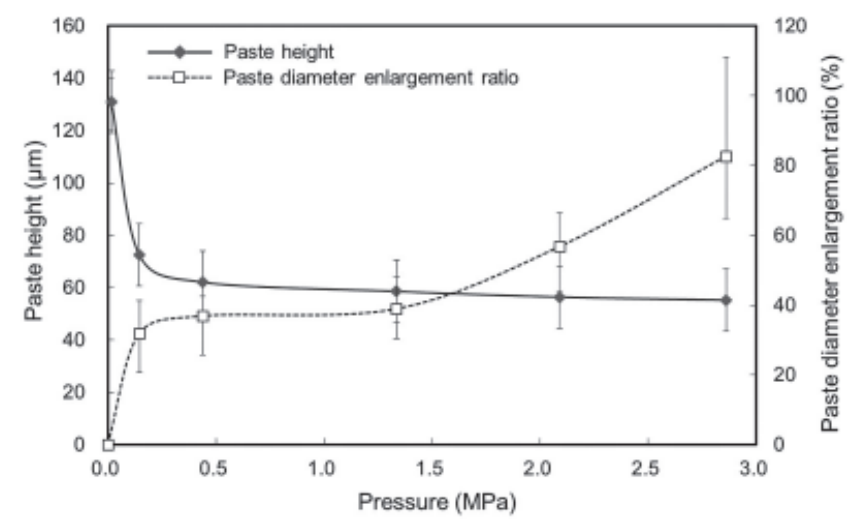

Fig. 9 Graphic representation of the bonding height load transition and diameter spread ratio. Pressure was at 0.02 to $2.89 \mathrm{MPa}$, curing was heated continuously until $180^{\circ} \mathrm{C}$ is exceeded. 
(a)

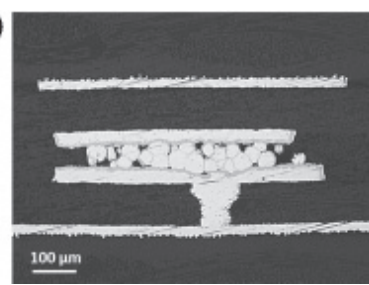

(b)

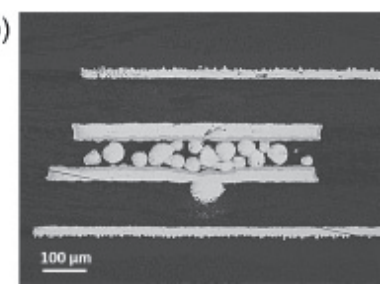

Fig. 10 Cross sectioning of $\mathrm{Cu}$ fillers conditions between the upper and lower pads by TEG boards. (a), (b) are good condition both, however filler aggregated state of $\mathrm{Cu}$ particles are observed a little different.

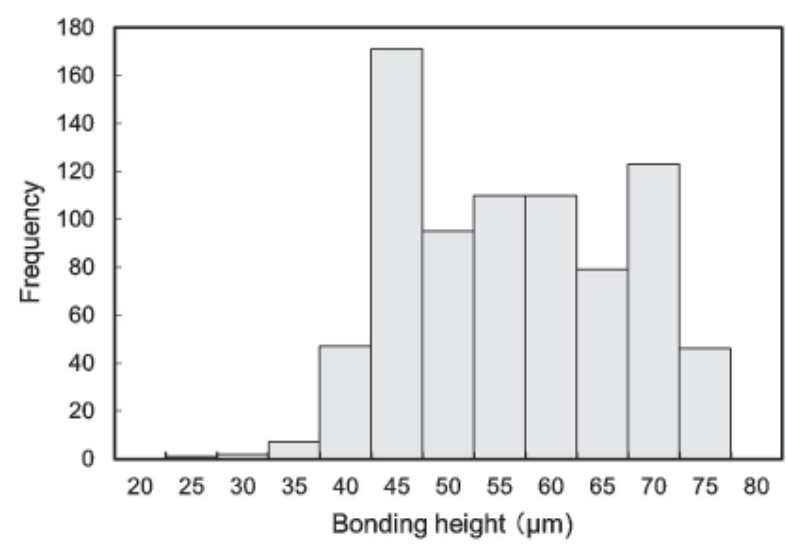

Fig. 11 Histogram of bonding height between the upper and lower pads.

The difference on the aggregated state of the $\mathrm{Cu}$ fillers can be observed and the height variation between the upper and lower pad occurring by the scatter of aggregation was studied. Fig. 11 shows the histogram of the distribution of the height between the 791 bonding pads with a good electrical resistance. From these distributions, we found that the maximum height, the minimum height, the average height and the standard deviation were respectively $75 \mu \mathrm{m}, 25 \mu \mathrm{m}, 54 \mu \mathrm{m}$ and $10.7 \mu \mathrm{m}$. Therefore, for an optimum electrical resistance the bonding height tolerance should fluctuate within a $50 \pm 25 \mu \mathrm{m}$ range.

This result almost matches the $60 \mu \mathrm{m}$ crushed state of the paste after increasing the load in Fig. 8. When a paste is applied to the actual circuit board, the scatter of board thickness is inevitable. Circuit boards requiring new interconnected structures could became high-multilayer thick boards (4 to $6 \mathrm{~mm}$ ) and in some cases, the thickness scatter is near $\pm 100 \mu \mathrm{m}$. In this case, the board thickness has to be uniform and the paste needs to tolerate the bonding height scatter. This experiment showed that the compression state of the paste can allow a $\pm 50 \mu \mathrm{m}$ scatter tolerance for an average height. The tolerance range of this paste is wider than the one set for the compression type paste from our previously study ${ }^{12)}$ as it need to maintain a proper layering condition. In addition, a sufficient bonding margin was found as this paste absorbed the thickness scatter to realize a new structure.

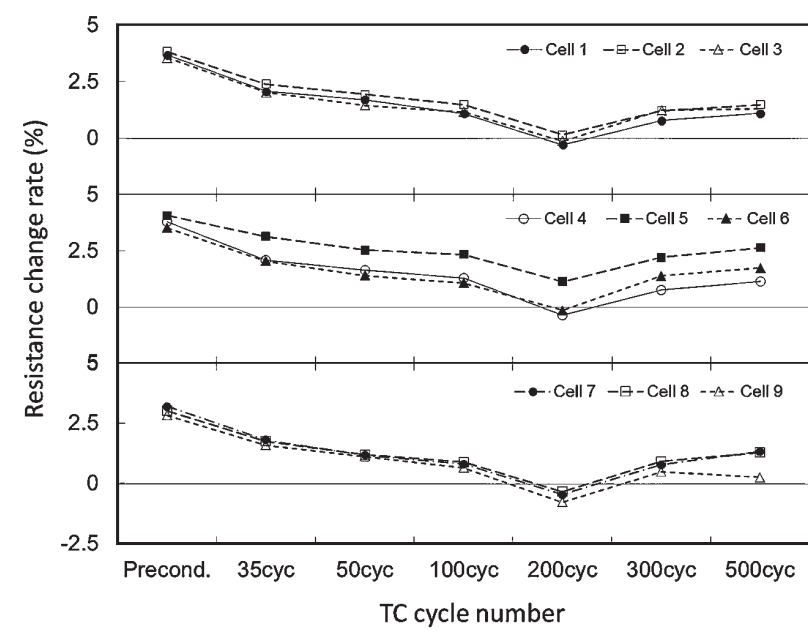

Fig. 12 Measurement result of electrical resistance by the TC test.

Finally the paste long-term reliability was studied. Fig. 12 shows the measurement results of the resistance electrical after 500 thermal cycles for each cells. It shows a stable 5\% changing rate which is considerably smaller than the $\pm 10 \%$ maximum value. By coating the $\mathrm{Sn}-\mathrm{Bi}$ on the surface as a conductive filler we can reach an effective alloying and high reliable connection condition is possible.

\section{Conclusions}

In this paper, the bonding conditions of composite circuit board structures with a melting-point-change type conductive paste were studied. The results are summarized below:

An Optimal bonding conditions allows a $\pm 10 \%$ electrical stability.

An improvement of the cohesive force by adding a thixotropic agent increases the bonding strength by $42 \%$.

A $1.5 \mathrm{MPa}$ or less load of is the best condition to maintain the paste diameter unchanged.

These results show that with this paste, it is now possible to create a bonding in a relatively low load region and at the same time the pressure applied to the bonding sheet can be reduced and the shape of the paste bonding part stabilized.

The bonding height tolerance is at around $50 \pm 25 \mu \mathrm{m}$ and there is only $5 \%$ electrical resistance variation after 500 thermal cycles.

\section{References}

1) Y. -D. Chiu and W. -P. Dow: Journal of Electrochem. Soc., 160-12 (2013) D3021-3027.

2) Echigo and M. Hirai: Panasonic Technical Journal, 55-2 (2009) 119123.

3) Y. Fukuoka, K. Sasaoka and T. Motomura: Journal of the Japan Institute of Electronics Packaging, 11-4 (2008) 260-270.

4) D. Andoh: Journal of the Japan Institute of Electronics Packaging, 3-7 (2000) 557-562. 
5) H. Kamiya, T. Miyake, H, Kobayashi and K. Kondo: DENSO Technical Review, 11-2 (2006) 103-107.

6) Y. Yazaki, T. Yokochi, R. Kataoka, K. Suzuki and K. Kondo: DENSO Technical Review, 10-2 (2005) 85-89.

7) M. Okamoto, A. Ito, K. Inoue. T. Kido, S. Takenaka and N. Ozawa: Proc. 19th. The Japan Institute of Electronics Packaging Annual Meeting, 2005, p17B-09.

8) Y. Oka, T. Kasuga, H. Tomioka, S. Uehara, J. J. Park, N. Uenishi and Y. Okuda: SEI Technical Review, 75 (2012) p106-109.

9) J. M. Lauffer and K. Knadle: Proc. IMAPS, 2014, p141-147.

10) R. N. Das, F. D. Egitto, J. M. Lauffer, D. Poliks and V. R. Markovich: Proc. IEEE 59th Electronic Components and Technology Conference, 2009, p180-187.
11) K. Kakizawa: Proc. 25th. The Japan Institute of Electronics Packaging, 2011, p10D-08.

12) K. Sugimoto, T. Nakagawa, S. Sugano, M. Watanabe and H. Honma: Materials Science and Technology of Japan, 54-2 (2017) 7074.

13) S. Tani, M. Yamanaka and S. Hashimoto: Journal of thermosetting plastics, Japan, 14-1 (1993) 28-39

14) A.Sakaida, A.Ueno, K.Isonishi, S.Nishino, and N.Horikawa: Proc. Strength and Fracture of Materials, 2011, p12-20.

\section{Mail Address}

Kaoru SUGIMOTO sugimoto.kao@jp.fujitsu.com 